GRASAS Y ACEITES 68 (1)

January-March 2017, e182

ISSN-L: 0017-3495

doi: http://dx.doi.org/10.3989/gya.1161162

\title{
An explanation for the natural de-bittering of Hurma olives during ripening on the tree
}

\author{
E. Susamci ${ }^{\mathrm{a}}$, C. Romero ${ }^{\mathrm{b}}$, O. Tuncay ${ }^{\mathrm{c}}$ and M. Brenes ${ }^{\mathrm{b}, \bigotimes}$ \\ ${ }^{a}$ Olive Research Institute, Üniversite Caddesi No: 4335100 Bornova. Izmir, Turkey \\ ${ }^{b}$ Instituto de la Grasa (IG-CSIC), Campus University Pablo de Olavide, Ctra. Utrera km 1, 41013-Seville, Spain \\ ${ }^{c}$ Faculty of Agriculture, Ege University, 35100 Izmir, Turkey \\ ${ }^{\square}$ Corresponding author: brenes@cica.es
}

Submitted: 02 November 2016; Accepted: 14 December 2016

SUMMARY: Harvested olives require further processing to make them edible due to their content in the bitter substance oleuropein. However, some olives of the Erkence cultivar naturally de-bitter on the tree giving rise to the so-called Hurma olives. In this study, the evolution of the chemical characteristics of Erkence and Hurma olives harvested from the northeast and southwest area of trees located in the Karaburun Peninsula was assayed. It was confirmed that the oleuropein content in Hurma olives was much lower $(<2000 \mathrm{mg} / \mathrm{kg}$ fresh weight $)$ than Erkence, which reached $35.000 \mathrm{mg} / \mathrm{kg}$ fresh weight at the beginning of the season. In addition, no free or polymerized anthocyanins were found in Hurma fruit in contrast to ripened Erkence fruit. The concentration of glucose was also lower in Hurma than Erkence olives. These results suggest that the enzymatic oxidation of oleuropein could be responsible for the natural de-bittering of Hurma olives during their ripening on the tree.

KEYWORDS: Anthocyanin; Bitterness; Olive; Phenolic compounds; Sugar

RESUMEN: Una explicación para el desamargado natural de aceitunas Hurma durante su maduración en el árbol. Las aceitunas recién cogidas del árbol necesitan ser procesadas para hacerlas comestibles, debido a su contenido en el compuesto amargo oleuropeína. Sin embargo, algunas aceitunas de la variedad Erkence desamargan de forma natural en el árbol dando lugar a las aceitunas conocidas como Hurma. En este trabajo se han analizado las características químicas de aceitunas Erkence y Hurma recolectadas de la zona noreste y suroeste de árboles situados en la provincia de Karaburun. Se ha confirmado que el contenido en oleuropeína de aceitunas Hurma es muy inferior $(<2000 \mathrm{mg} / \mathrm{kg}$ ) que Erkence, las cuales alcanzaron una concentración en dicha sustancia hasta de $35.000 \mathrm{mg} / \mathrm{kg}$ al principio del periodo de maduración. Además, no se encontraron en aceitunas Hurma antocianinas ni libres ni polimerizadas, a diferencia de Erkence. Estos resultados indican que la oxidación enzimática de la oleuropeína podría ser la responsable de la eliminación del amargor de forma natural en aceitunas Hurma durante su maduración en el árbol.

PALABRAS CLAVE: Aceituna; Amargor; Antocianina; Azúcar; Compuestos fenólicos

ORCID ID: Susamci E http://orcid.org/0000-0003-1956-4634, Romero C http://orcid.org/0000-0003-1885-1770, Tuncay O http://orcid.org/0000-0002-5218-1056, Brenes M http://orcid.org/0000-0001-7419-4061

Citation/Cómo citar este artículo: Susamci E, Romero C, Tuncay O. Brenes M. 2017. An explanation for the natural debittering of Hurma olives during ripening on the tree. Grasas Aceites 68, e182. http://dx.doi.org/10.3989/gya.1161162

Copyright: (C) 2017 CSIC. This is an open-access article distributed under the terms of the Creative Commons Attribution (CC-by) Spain 3.0 License. 


\section{INTRODUCTION}

Olives are generally produced in Mediterranean countries, where there are about 8 million hectares of cultivated olives trees. Olive oil and table olives are the two food products obtained from these fruits, which are key components of the Mediterranean diet. Olives cannot be consumed immediately after harvest because of their high phenolic content, especially the bitter glucoside oleuropein (Ramírez et al., 2014). To remove the bitter taste, some processing methods have been developed such as Spanish-style green olives and California black oxidized olives which consist of removing the bitterness by treating the fruit with a dilute solution of $\mathrm{NaOH}$. Other trade preparations such as green and black natural olives involve the direct brining of the fruit without any alkaline treatment, and the bitterness disappears slowly over time (Ramírez et al., 2015).

There is an olive cultivar in Turkey, called Erkence, which can become edible naturally while still on the tree, when it is grown in the Karaburun Peninsula. This "natural de-bittering" gives rise to olives called Hurma (Susamci, 2011). From October to December, the color of the skin and the flesh of the fruits become dark-brown, they lose some water and fall to the ground. The fruits of other varieties grown in the same region cannot de-bitter on the tree. Although Erkence fruits have the ability to de-bitter on the tree, not all of them undergo this process. Hurma olives that fall to the ground are continuously collected by growers, and they can be directly consumed without any post-harvest processing. Therefore, these olives are a healthy food product suitable for people seeking salt-free table olives.

There are only a few studies on Hurma olives, whose de-bittering on the tree has been associated to changes in phenolic compounds during the late period of maturation (Aktas et al., 2014a). These olives possess a higher linoleic acid content than Erkence, which might be an indication of increased desaturase enzyme activity during the natural debittering phase (Aktas et al., 2014b). In addition, it has been suggested that the fungus named Phoma oleae could be involved in the hydrolysis of oleuropein (Panagou, 2006), although it is not the prevalent microorganism on the surface of Hurma olives (Sozvilen and Baysal, 2016). There are many sweet olive varieties such as Dhokar, Gordal/Sevillano and Trouba Thassos but all of them need post-harvest processing to make them palatable (Panagou, 2006; Menz and Vriesekoop, 2010; Rigane et al., 2011). In contrast, Hurma olives are currently consumed after harvesting without any brining process.

The phenomenon of Hurma olive formation on the tree of the Erkence fruit is still unknown. According to growers, climate is a very important factor for the development of this process. They claim that natural de-bittering needs northern winds and dew.
In this study, the effects of fruit location on the tree and the altitude and distance from the sea of the orchards, on some chemical compounds in Hurma and Erkence olives grown in the Karaburun Peninsula were investigated. An explanation for the natural debittering of the Hurma olives as well as their color changes during formation has been proposed.

\section{MATERIALS AND METHODS}

\subsection{Olive samples}

Two orchards located in the Karaburum Peninsula (Turkey) with olive trees of the Erkence cultivar were chosen for the experiments due to their availability for Hurma olive formation. Orchard A was cultivated at sea level (100 m distance from the sea, latitude: $38^{\circ} 32^{\prime} 56^{\prime \prime} \mathrm{N}$, longitude: $\left.26^{\circ} 34^{\prime} 56^{\prime \prime} \mathrm{E}\right)$ and orchard B at $174 \mathrm{~m}$ above the sea $\left(1.4 \mathrm{~km}\right.$ distance from the sea, latitude: $38^{\circ}$ $33^{\prime} 42^{\prime \prime}$ N, longitude: $\left.26^{\circ} 33^{\prime} 5^{\prime \prime} \mathrm{E}\right)$. Both Hurma (naturally de-bittered Erkence) and Erkence (not naturally de-bittered) olives were collected manually during the maturation period from the northeast (facing the sea) and southwest (inland) sides of triplicate trees. Olive samples were picked for eleven weeks in the first season (2014/15) and nine weeks in the second season (2015/16), starting from the end of September. It must be noted that both Hurma and Erkence olives were taken from the same trees throughout the maturation period. Fruit samples were transferred to the laboratory in PE bags, and the maturity index and moisture were determined. For other analyses, olives were frozen at $-20{ }^{\circ} \mathrm{C}$ and freeze dried, after the removal of the stones.

\subsection{Maturity index}

One hundred olives were selected at random, classified into seven groups according to their color (green, black, reddish brown, etc.) and the number of fruits in each group was determined. Black fruits were cut to examine the percentage of black or purple coloring in the flesh. The number of fruits in each class was multiplied by the coefficient of the class, and the maturity index was calculated according to the formula given by Morello et al., (2005).

\subsection{Analysis of moisture}

The water content was measured on fresh olive paste by drying in an oven at $105^{\circ} \mathrm{C}$ until constant weight was obtained.

\subsection{Analysis of phenolic compounds}

Around $1.5 \mathrm{~g}$ of freeze dried olive pulp was mixed in an Ultra-turrax homogenizer with $30 \mathrm{~mL}$ of dimethylsulfoxide (DMSO). After $30 \mathrm{~min}$ of resting contact, 
the mixture was centrifuged at $6000 \mathrm{~g}$, and $0.25 \mathrm{~mL}$ of the supernatant were diluted with $0.5 \mathrm{~mL}$ of DMSO plus $0.25 \mathrm{~mL}$ of $0.2 \mathrm{mM}$ syringic acid in DMSO (internal standard). The mixture was filtered through a $0.22 \mu \mathrm{m}$ pore size nylon filter, and an aliquot $(20 \mu \mathrm{L})$ was injected into the chromatograph. The chromatographic system consisted of a Waters 717 plus autosampler, a Waters 600E pump and a Waters 996 diode array detector (Waters Inc. Milford, MA, USA). A Spherisorb ODS-2 (5 $\mu \mathrm{m}$, $25 \mathrm{~cm}$ x $4.6 \mathrm{~mm}$ i.d., Waters Inc.) column was used. Separation was achieved using an elution gradient with an initial composition of $90 \%$ water $(\mathrm{pH}$ adjusted to 2.7 with phosphoric acid) and $10 \%$ methanol. The concentration of the latter solvent was increased to 60,70 and $100 \%$ in 5 -min periods. A flow rate of $1 \mathrm{~mL} / \mathrm{min}$ and a temperature of $35^{\circ} \mathrm{C}$ were used. Chromatograms were recorded at $280 \mathrm{~nm}$ for phenolic compounds (Ramírez et al., 2014).

The identification of the phenolic compounds in the extract was made using a HPLC-MS system that consisted of a Waters 2695 Alliance with a pump, column heater and autosampler modules, and the detection was carried out with a Waters 2998 photodiode array detector and a mass single-quadrupole detector (QDa, Waters, USA). The QDa mass detector was operated in the negative mode (ESI-), the capillary voltage was set at $0.8 \mathrm{kV}$, the cone voltage to $15 \mathrm{~V}$, and nitrogen was used as nebulizer gas with de-solvation temperature set at $600^{\circ} \mathrm{C}$. The flow rate was $1 \mathrm{~mL} / \mathrm{min}$, and the column, solvent and gradient conditions were the same as mentioned above.

\subsection{Total pigment analysis}

After dissolving $0.1 \mathrm{~g}$ of freeze-dried fruit sample in $1.5 \mathrm{~mL}$ of $1 \mathrm{M} \mathrm{HCl}$, the mixture was first vortexed for $1 \mathrm{~min}$., sonicated for $1 \mathrm{~min}$, vortexed again for $1 \mathrm{~min}$., and then centrifuged. The supernatant was then filtered through a $0.22 \mu \mathrm{m}$ pore size filter, and diluted 10 fold with $1 \mathrm{M} \mathrm{HCl}$. The absorbance spectrum of the extracts $\left(\lambda_{400}-\lambda_{700}\right)$ was measured using a Shimadzu UV-vis spectrophotometer, which was equipped with a computer software program to calculate the CIELAB parameters (Romero and Bakker, 2000).

\subsection{Analysis of free anthocyanins}

Anthocyanins were extracted from a $0.1 \mathrm{~g}$ sample of freeze-dried olive sample with a solution of methanol:hydrochloric acid $\left(99: 1, \mathrm{v} / \mathrm{v}, 0^{\circ} \mathrm{C}\right)$ as described elsewhere (Romero et al., 2002). Briefly, the mixture was centrifuged at $9000 \mathrm{~g}$ for $5 \mathrm{~min}\left(10^{\circ} \mathrm{C}\right)$, and the extraction was repeated 6 times. The methanolic extracts were concentrated under vacuum at $30{ }^{\circ} \mathrm{C}$ to water residue and made up to $25 \mathrm{~mL}$ volume with acidified dionized water. A washing step with hexane was required to remove fat from the extract, and the residual solvent was eliminated by purging nitrogen. An aliquot of $20 \mu \mathrm{L}$ was injected into the chromatograph. The HPLC system consisted of a Waters 2695 Alliance with a pump, column heater $\left(40^{\circ} \mathrm{C}\right)$ and autosampler modules, and the detection was carried out with a Waters 2998 photodiode array detector (Waters Inc.). A $25 \mathrm{~cm} \times 4.6 \mathrm{~mm}$ i.d., $5-\mu \mathrm{m}$ Extrasil ODS-2 (Technokroma, Barcelona, Spain) column was used and the elution conditions were as follows: flow rate $=1 \mathrm{ml} / \mathrm{min}$; solvent $\mathrm{A}$, water with $1 \%$ perchloric acid, solvent $\mathrm{B}$, methanol. The mobile phase consisted initially of $80 \%$ of A; using a linear gradient, the concentration of methanol was increased to $50 \%$ over $35 \mathrm{~min}$, to $98 \%$ at $40 \mathrm{~min}$, held for 2 min at $98 \%$ of B to wash the column, and then returned to the initial conditions $(20 \%$ of $\mathrm{B})$ for $10 \mathrm{~min}$. Chromatograms were recorded at $520 \mathrm{~nm}$.

\subsection{Analysis of sugars}

Freeze-dried fruit $(1 \mathrm{~g})$ was mixed with $20 \mathrm{~mL}$ of boiling water and vortexed for $1 \mathrm{~min}$, kept in an ultrasonic bath for $3 \mathrm{~min}$, vortexed again for $1 \mathrm{~min}$, and the mixture was centrifuged at $9000 \mathrm{~g}$ for $5 \mathrm{~min}$. The mixture was filtered through filter paper using a vacuum, and another $20 \mathrm{~mL}$ of hot water were added and filtered again. The filtrate was then transferred to a $50 \mathrm{~mL}$ volumetric flask containing $2 \mathrm{~mL}$ of sorbitol as internal standard $(7.5 \%, \mathrm{w} / \mathrm{v})$ and made up to volume. The solution was kept at $5{ }^{\circ} \mathrm{C}$ for $24 \mathrm{~h}$ to remove lipids and subsequently filtered through a $0.22 \mu \mathrm{m}$ pore size nylon filter. Two milliliters of the clarified liquid were put into contact with $1 \mathrm{~g}$ of the acidic resin Amberlite IR-120 and $1 \mathrm{~g}$ of the basic resin Amberlite IRA-93. Samples were shaken occasionally for $30 \mathrm{~min}$, and $1 \mathrm{~mL}$ of the solution was centrifuged at $9000 \mathrm{~g}$ for $3 \mathrm{~min}$. An aliquot of $20 \mu \mathrm{L}$ was injected into the chromatograph. The HPLC system consisted of a Waters 2695 Alliance with a pump and autosampler included; the detection was performed with a Waters 410 refractive index detector. A Rezex RCM-Monosaccharide Ca+ (8\%) column $(300 \times 7.8 \mathrm{~mm}$ i.d., Phenomenex $)$ held at $85^{\circ} \mathrm{C}$ and deionized water as eluent at $0.6 \mathrm{~mL} / \mathrm{min}$ were used (Medina et al., 2007).

\subsection{Statistical analysis}

Statistical comparisons of the mean values for each experiment were performed by one-way analysis of variance (ANOVA), followed by the Duncan's multiple range test $(p<0.05)$ using Statistica software version 8.0 (Stat-Soft, 2001).

\section{RESULTS AND DISCUSSION}

The qualitative HPLC-MS analysis of olive extracts allowed for the identification of 11 phenolic compounds in Erkence and Hurma fruit, and the 
quantification of these substances by HPLC-DAD confirmed oleuropein as the main compound in olives throughout their ripening period (Ramírez et al., 2014; Talhaoui et al., 2015). Figure 1 shows the content of oleuropein in Erkence fruit during the ripening phase on olive trees cultivated in two different locations for two seasons. First, it must be noted that previous studies reported a very much lower concentration of oleuropein in Erkence olives that the content which is depicted in Figure 1 (Arslan, 2012; Aktas et al., 2014a). In fact, the latter researchers found a higher concentration in hydroxtyrosol and apigenin than oleuropein in these olives; whereas we did not detect the presence of these substances by using HPLC-MS.

The concentration of oleuropein decreased significantly during ripening in Erkence olives during the two seasons, which was more pronounced from the first to the 5th-7th week, which is a pattern previously described for other olive varieties (Menz and Vriesekoop, 2010; Talhaoui et al., 2015) but not in Erkence fruit (Aktas et al., 2014a).

Regarding the orchard location, both orchards are cultivated in the Karaburun Peninsula (Izmir, Turkey) under common Mediterranean climate characteristics with drought conditions, and orchard A lying near the sea and B in the mountains. The concentration of oleuropein was higher in the olives harvested from orchard B than A during the first week of the 2014/2015 season (Figure 1) but the opposite trend was observed during the 2015/2016 season, and no significant differences were found for mature olives (weeks 5-11). The effect of cultivation environment on the phenolic composition of fruits and leaves has been widely reported but many contradictory results have been found. Olive oils from fruit grown at high altitude had a higher content in phenolic compounds than those at a low altitude (Di Vaio et al., 2013), and vice-versa (Mousa and Gerasopoulos, 1996). Contradictory results have also been reported for the accumulation of anthocyanins in berries (Guerrero-Chavez et al., 2015; Zoratti et al., 2015). Phenolic compounds contribute to the protection of plants against UV radiation, and leaves and fruit cultivated at high altitude are currently richer in these substances. However, many other variables affect the content of phenolic compounds in plants such as soil, climate, and agronomic conditions.

In this study, samples of Erkence olives were collected from the northeast and southwest orientation of trees cultivated in both orchards A and B. No effect on the oleuropein composition due to tree orientation was found (Figure 1). Gómez-delCampo and García (2012) obtained a higher phenolic concentration in olive oils extracted from fruit located at higher layers of the olive trees than lower layers, and Romero et al., (2016) reported that olive oils from sunny areas had a higher concentration
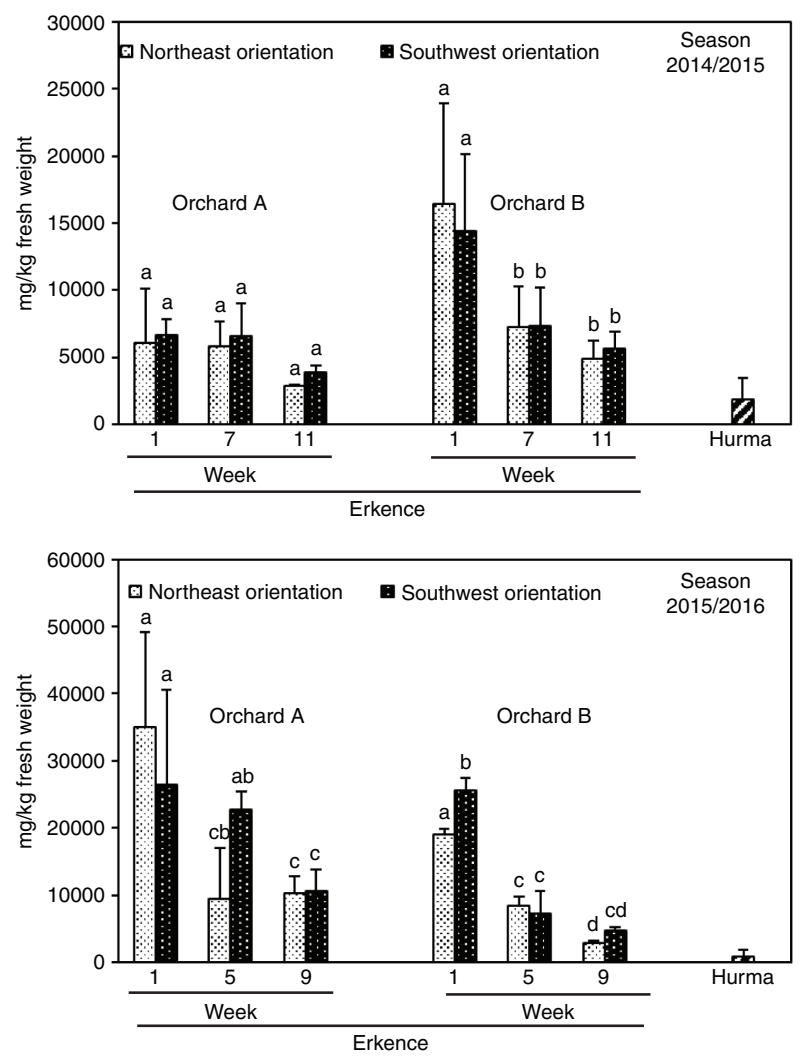

FIGURE 1. Effect of olive tree orientation and ripening on the concentration $(\mathrm{mg} / \mathrm{kg}$ fresh weigh) of oleuropein in Erkence and Hurma olives. Three samples of Erkence olives were analyzed for each sampling time. Eight samples of Hurma olives were collected from orchards A and B at week 7 during the season 2014/2015, and 11 samples at weeks 5 and 9 during the season 2015/2016. Vertical bars with different letters indicate significant differences according to Duncan's multiplerange test $(\mathrm{p}<0.05)$

of these substances than those from shady areas. A trend was observed for the rest of the phenolic compounds analyzed in Erkence olives (Table 1), although it was not statistically significant. It must be noted that the synthesis of phenolic compounds is influenced by solar radiation, the longer the hours of exposure to solar radiation of fruit and leaves, the higher the concentration of certain phenolic compounds will be found in these materials (Spayd et al., 2002; Morales et al., 2010).

Similar to oleuropein, hydroxytyrosol 1-glucoside, oleuropein aglycon, ligustroside, rutin, comselogoside and others decreased their concentrations in Erkence olives with ripening. In contrast, the hydroxytyrosol 4-glucoside content increased with olive maturation as has been previously reported for other olive varieties (Romero et al., 2002). The concentration of all these compounds was also higher in olives harvested during the second than the first season (Table 1), which also occurred with the content in oleuropein (Figure 1). 
TABLE 1. Influence of harvesting season and olive tree orientation on the concentration of phenolic compounds ( $\mathrm{mg} / \mathrm{kg}$ fresh weight) other than oleuropein during ripening of Erkence and Hurma olives from orchard B

\begin{tabular}{|c|c|c|c|c|c|c|c|}
\hline & $\begin{array}{c}\text { Oleuropein } \\
\text { aglycon }\end{array}$ & $\begin{array}{c}\text { Hydroxytyrosol } \\
\text { 1-glucoside }\end{array}$ & $\begin{array}{c}\text { Hydroxytyrosol } \\
\text { 4-glucoside }\end{array}$ & Ligustroside & Rutin & Comselogoside & Others $^{\mathrm{a}}$ \\
\hline \multicolumn{8}{|l|}{ (2014/2015) Erkence } \\
\hline Week $1(\mathbf{N})^{d}$ & $3315 \mathrm{a}$ & $110 \mathrm{a}$ & $408 \mathrm{a}$ & $777 \mathrm{a}$ & $568 \mathrm{a}$ & $189 \mathrm{a}$ & $69 \mathrm{a}$ \\
\hline Week 1 (S) & $4421 \mathrm{a}$ & $108 \mathrm{a}$ & $285 \mathrm{a}$ & $754 \mathrm{a}$ & $779 \mathrm{a}$ & $201 \mathrm{a}$ & $109 a$ \\
\hline Week 7 (N) & $1043 b$ & $25 b$ & $585 \mathrm{a}$ & $334 b$ & $324 b$ & $101 b$ & $48 \mathrm{a}$ \\
\hline Week 7 (S) & $1504 b$ & $23 b$ & $492 \mathrm{a}$ & $383 b$ & $313 b$ & $123 b$ & $42 \mathrm{a}$ \\
\hline Week $11(\mathrm{~N})$ & $1000 \mathrm{~b}$ & $24 \mathrm{~b}$ & $466 \mathrm{a}$ & $232 b$ & $331 b$ & $68 \mathrm{~b}$ & $113 \mathrm{a}$ \\
\hline Week 11 (S) & $949 b$ & $35 \mathrm{~b}$ & $638 \mathrm{a}$ & $251 b$ & $324 b$ & $80 \mathrm{~b}$ & $94 \mathrm{a}$ \\
\hline Hurma (week 7) & $65 \pm 144^{\mathrm{b}}$ & $16 \pm 26$ & $191 \pm 104$ & $304 \pm 239$ & $161 \pm 141$ & $37 \pm 38$ & $11 \pm 11$ \\
\hline \multicolumn{8}{|l|}{ (2015/2016) Erkence } \\
\hline Week $1(\mathrm{~N})$ & $2044 a$ & $359 \mathrm{a}$ & $572 \mathrm{a}$ & $1174 a$ & $289 a$ & $123 a$ & $113 \mathrm{a}$ \\
\hline Week 1 (S) & $2662 a$ & $489 b$ & $739 a$ & $1365 \mathrm{a}$ & $567 \mathrm{~b}$ & $176 a$ & $194 \mathrm{ab}$ \\
\hline Week $5(\mathrm{~N})$ & $4030 \mathrm{a}$ & $259 \mathrm{ac}$ & $658 \mathrm{a}$ & $546 \mathrm{~b}$ & $202 \mathrm{a}$ & $118 b$ & $44 \mathrm{ac}$ \\
\hline Week 5 (S) & $5168 b$ & $220 \mathrm{acd}$ & $843 a$ & $518 b$ & $306 \mathrm{a}$ & $117 b$ & $70 \mathrm{ab}$ \\
\hline Week 9 (N) & $2395 \mathrm{a}$ & $99 \mathrm{~d}$ & $613 a$ & $180 \mathrm{c}$ & $171 \mathrm{a}$ & $71 \mathrm{~b}$ & $49 \mathrm{ac}$ \\
\hline Week 9 (S) & $2440 \mathrm{a}$ & $150 \mathrm{~d}$ & $1344 \mathrm{a}$ & $249 \mathrm{c}$ & $176 \mathrm{a}$ & $70 \mathrm{~b}$ & $98 \mathrm{ab}$ \\
\hline Hurma (weeks 5 and 9) & $123 \pm 286^{\mathrm{c}}$ & $13 \pm 18$ & $247 \pm 156$ & $202 \pm 143$ & $36 \pm 45$ & $19 \pm 17$ & $6 \pm 18$ \\
\hline
\end{tabular}

${ }^{a}$ Others is the sum of verbascoside, caffeoyl ester of secologanoside, caffeic and $p$-coumaric acids.

${ }^{\mathrm{b}}$ Mean of 5 samples \pm standard deviation.

${ }^{c}$ Mean of 11 samples \pm standard deviation.

d N, northeast; S, southwest. Column values for each season followed by the same letter did not differ at the $5 \%$ level according to Duncan's multiple-range test.

Some of the Erkence olives shrivel and lose moisture and bitterness during their ripening on the tree, giving rise to the well-appreciated Hurma olives. The data depicted in Figure 1 confirm the low concentration of oleuropein in Hurma olives in comparison with Erkence fruit for the two seasons analyzed. The contents of oleuropein aglycon, hydroxytyrosol glucosides and the rest of the phenolic compounds were also much lower in Hurma than Erkence olives (Table 1). A previous study reported a low concentration of oleuropein in Hurma olives but also a very high content in hydroxytyrosol and apigenin (Aktas et al., 2014a), whose presence in Hurma olives has not been confirmed in this work by using HPLC-MS.

To our knowledge, there is not a clear explanation for the natural de-bittering of Hurma olives, although it has been suggested that the infection of the fruit by Phoma olea could be a possibility (Atkas et al., 2014b). One of the phenomena which occurred during the transformation of Erkence to Hurma olives is a decrease in moisture in the fruit. This parameter ranged in Hurma olives between 30-40\% (Figure 2) whereas Erkence had around 50\%. Phoma fungus causes irregular necrotic patches in fruits, a drop in phenolic compounds and an increase in peroxidase and polyphenoloxidase activity (Bugbee, 1975; Hura et al., 2014). Also, an anthracnose disease originated by Colletottrichum acutatum gives rise to desiccated fruits (Moral et al., 2014) but

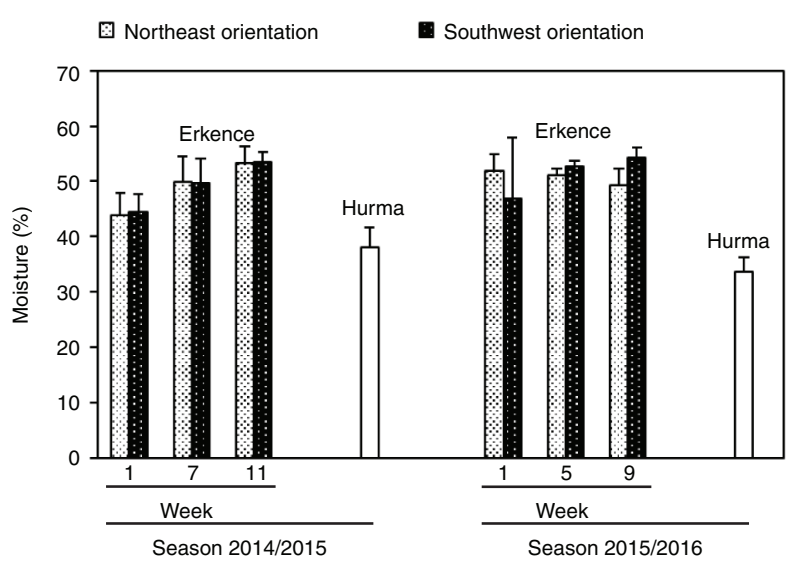

FIGURE 2. Effect of olive tree orientation and harvesting season on the moisture (\%) of Erkence and Hurma olives. Fruit were collected from orchard B. Five samples of Hurma olives were harvested at week 7 during the first season, and 11 samples of these olives were harvested at weeks 5 and 9 during the second season. Standard error is shown on the bars.

Hurma olives look like dry-salted olives rather than mummified fruit. Frost damage during the harvest period also produces olive shriveling, softening and water loss, and it could be another explanation for the formation of Hurma olives but it must be confirmed. In fact, frost causes cell death and dehydration in fruits and a high oxidation of cell contents 
may occur as a result of contact between oxidase enzymes and phenolic substrates, which has been reported for the decrease in the bitter taste in olive oils affected by freeze injuries (Morello et al., 2003).

Erkence olives change their color during ripening in a similar way to many other olive varieties. The surface color turns to yellow, purple and finally black as a consequence of anthocyanin synthesis that also continues inside the pulp. In contrast, Hurma olives change their color directly from green-yellow to brown or dark brown not only on their surface but also in their pulp. An explanation for these color changes in Hurma olives remains unsolved. Erkence olives with a maturation index of 3-4 had a significant content in anthocyanins (Table 2). This maturation index means olives with purple or black surface color and white color inside the pulp so that it was predictable to find anthocyanins in these olives, mainly cyanidin-3-rutinoside and cyanidin-3-glucoside (Romero et al., 2002). Surprisingly, free anthocyanins were not detected in
Hurma olives which were classified with a maturation index of 7. In addition, the color parameters $\left(L^{*}, a^{*}\right.$, $\left.b^{*}, \lambda_{520}\right)$ of olive extracts from Erkence and Hurma olives revealed that those from Erkence had a purple/ red color whereas those of Hurma had a slightly yellow color (Table 2). Anthocyanins are found free in raw olives and can be oxidized and polymerized during processing (Romero and others 2004). The results presented in Table 2 indicate the absence of these substances either free or polymerized in Hurma olives so that their dark brown color could be formed from the oxidation of $o$-diphenols, particularly oleuropein. The oxidation of the latter substance gives rise to nonbitter substances (García et al., 2008), and it has been proposed as the explanation for the de-bittering of black dry-salted and dried green olives (Ramírez et al., 2013; Piscopo et al., 2014).

Another difference found between Erkence and Hurma olives was their content in sugars (Table 3). As expected, glucose, fructose and mannitol were

TABLE 2. Color parameters $\left(\mathrm{L}^{*}, \mathrm{a}^{*}, \mathrm{~b}^{*}, \lambda_{520}\right)$ of an acidic extract of Erkence and Hurma olives, and concentration of anthocyanins ( $\mathrm{mg} / \mathrm{kg}$ fresh weight) in the pulp of

\begin{tabular}{|c|c|c|c|c|c|c|c|}
\hline \multirow[b]{2}{*}{ Olive type } & \multirow{2}{*}{$\begin{array}{c}\text { Maturity } \\
\text { index }\end{array}$} & \multicolumn{4}{|c|}{ Color parameters of extract } & \multicolumn{2}{|c|}{ Anthocyanins } \\
\hline & & $\mathbf{L}^{*}$ & $\mathbf{a}^{*}$ & $\mathbf{b}^{*}$ & $\lambda_{520}$ & Cyanidin-3-glucoside & Cyanidin-3-rutinoside \\
\hline Erkence & 3.8 & 72.7 & 51.4 & 13.0 & $>2$ & $341 \pm 145^{\mathrm{a}}$ & $1703 \pm 597$ \\
\hline Erkence & 3.2 & 83.9 & 28.2 & 3.6 & 0.42 & $173 \pm 6$ & $1030 \pm 97$ \\
\hline Erkence & 3.6 & 73.2 & 50.6 & 14.6 & 1.32 & $46 \pm 4$ & $292 \pm 13$ \\
\hline Hurma & 7 & 96.3 & 0.2 & 5.4 & 0.04 & $\mathrm{nd}^{\mathrm{b}}$ & nd \\
\hline Hurma & 7 & 96.7 & -0.4 & 8.2 & 0.05 & nd & nd \\
\hline Hurma & 7 & 97.0 & -0.5 & 6.3 & 0.05 & nd & nd \\
\hline
\end{tabular}

${ }^{\mathrm{a}}$ Standar deviation.

b nd, not detected.

TABLE 3. Concentration of main sugars ( $\mathrm{mg} / \mathrm{kg}$ fresh weight) in the pulp of Erkence and Hurma olives collected from orchard B

\begin{tabular}{lllcccc}
\hline & Olive type & Tree orientation & Week of harvesting & Glucose & Fructose & Mannitol \\
\hline Season 2014/2015 & & & & & \\
& Erkence & Northeast & 1 & $12901 \mathrm{a}$ & $4435 \mathrm{a}$ & $9380 \mathrm{a}$ \\
& Erkence & Southwest & 1 & $14295 \mathrm{a}$ & $4350 \mathrm{a}$ & $9760 \mathrm{ab}$ \\
& Erkence & Northeast & 11 & $8971 \mathrm{a}$ & $6304 \mathrm{a}$ & $4955 \mathrm{ab}$ \\
& Erkence & Southwest & 11 & $10297 \mathrm{a}$ & $7106 \mathrm{a}$ & $5193 \mathrm{abc}$ \\
& Hurma & Northeast & 11 & $2323 \mathrm{~b}$ & $4128 \mathrm{a}$ & $8570 \mathrm{a}$ \\
& Hurma & Southwest & 11 & $2539 \mathrm{~b}$ & $3256 \mathrm{a}$ & $8255 \mathrm{a}$ \\
& & & & & \\
& Erkence & Northeast & 1 & $8690 \mathrm{a}$ & $2333 \mathrm{a}$ & $2942 \mathrm{a}$ \\
& Erkence & Southwest & 1 & $9969 \mathrm{a}$ & $3527 \mathrm{a}$ & $4004 \mathrm{a}$ \\
& Erkence & Northeast & 8 & $9442 \mathrm{a}$ & $2557 \mathrm{a}$ & $4866 \mathrm{a}$ \\
& Erkence & Southwest & 8 & $9187 \mathrm{a}$ & $2383 \mathrm{a}$ & $2776 \mathrm{a}$ \\
& Hurma & Northeast & 9 & $1682 \mathrm{~b}$ & $2672 \mathrm{a}$ & $5056 \mathrm{a}$ \\
& Hurma & Southwest & 9 & $1928 \mathrm{~b}$ & $2145 \mathrm{a}$ & $4083 \mathrm{a}$ \\
\hline
\end{tabular}

${ }^{a}$ Data are the mean of triplicates (Erkence olives) or duplicates (Hurma olives). Column values for each season followed by the same letter did not differ at the $5 \%$ level of significance according to the Duncan's multiple-range test. 
the main free sugars detected in the olives (Marsilio et al., 2001), and a general decrease from week 1 to weeks 8-11 was observed for Erkence olives in agreement with previous reports (Menz and Vriesekoop, 2010). A trend to higher sugar content in Erkence olives harvested from the southern area of the trees than the north was also detected although it was not always significant. Surprisingly, the content of glucose was much lower in Hurma than Erkence olives but this effect was not detected for the concentration of fructose and mannitol, and it was not observed in a previous study (Aktas et al., 2014b). It is wellknown that respiration is enhanced in freeze-injured and fungus infected fruits (Fuchs et al., 1975; Liu et al., 2005), and olives consume mannitol and fructose at a higher rate than glucose during their postharvest period (García et al., 1995). Hence, Hurma olives de-bitter during their ripening on the tree and they also consume a high content of glucose during this period but not mannitol or fructose.

\section{CONCLUSIONS}

This study confirmed the low concentration of phenolic compounds in Hurma olives, particularly the bitter glucoside oleuropein, in comparison with that of Erkence fruit. Moreover, dark-brown Hurma olives did not contain free or polymerized anthocyanins as opposed to black Erkence which possessed free cyanidin-3-rutinoside and cyaniding-3-glucoside. These pigments therefore are not involved in the dark color of Hurma olives but polymers formed during the enzymatic oxidation of oleuropein must be responsible for this dark-brown color. Therefore, Hurma olives lose their bitterness during maturation on the tree due to the enzymatic oxidation of oleuropein, which gives rise to non-bitter substances, as it has also been demonstrated for the de-bittering of black dry-salted and dried green olives (Ramírez et al., 2013; Piscopo et al., 2014).

\section{ACKNOWLEDGMENTS}

This research was supported by the Projects TAGEM/HSGYAD/14/A05/P02/59 (Republic of Turkey, Ministry of Food, Agriculture and Livestock), and AGL-2013-42739-R (Spanish Government and the European Union FEDER funds).

\section{REFERENCES}

Aktas A B, Ozen B, Tokatli F, Sen I. 2014a. Phenolics profile of a naturally debittering olive in comparison to regular olive varieties. J. Sci. Food Agric. 94, 691-698. http://dx.doi. org/10.1002/jsfa.6308

Aktas A B, Ozen B, Tokatli F, Sen I. 2014b. Comparison of some chemical parameters of a naturally debittered olive (Olea europaea L.) type with regular olive varieties. Food Chem. 161, 104-111. http://dx.doi.org/10.1016/j. foodchem.2014.03.116
Arslan D. 2012. Physico-chemical characteristics of olive fruits of Turkish varieties from the province of Hatay. Grasas Aceites 63, 158-166. http://dx.doi.org/10.3989/gya.071611

Bugbee WM. 1975. Peroxidase, polyphenoloxidase, and endogalacturonate transeliminase activity in different tissues of sugar-beet infected with Phoma betae. Can. J. Bot. 53, 1347-1351. http://dx.doi.org/10.1139/b75-163

Di Vaio C, Nocerino S, Paduano A, Sacchi R. 2013. Influence of some environmental factor son drupe maturation and olive oil composition. J. Sci. Food Agric. 93, 1134-1139. https:// doi.org/10.1002/jsfa.5863

Fuchs Y, Zauberman G, Yanko U. 1975. Freeze injuries in avocado fruit. Hortscience 10, 64-65.

García P, Brenes M, Romero C, Garrido A. 1995. Respiration and physicochemical changes in harvested olive fruits. J. Horticult. Sci. 70, 925-933. http://dx.doi.org/10.1080/ 14620316.1995 .11515368

García A, Romero C, Medina E, García P, de Castro A, Brenes M. 2008. Debittering of olives by polyphenol oxidation. J. Agric. Food Chem. 56, 11862-11867. http://dx.doi. org/10.1021/jf802967y

Gómez-del-Campo M, García J M. 2012. Canopy fruit location can affect olive oil quality in "Arbequina" hedgerow orchards. J. Am. Oil Chem. Soc. 89, 123-133. http://dx.doi. org/10.1007/s11746-011-1900-2

Guerrero-Chavez G, Scampicchio M, Andreotti C. 2015. Influence of the site altitude on strawberry phenolic composition and quality. Sci. Hortic. 192, 21-28. http://dx.doi. org/10.1016/j.scienta.2015.05.017

Hura K, Hura T, Baczek-Kwinta R, Grzesiak M, Plazek A. 2014. Induction of defense mechanisms in seedlings of oilseed winter rape inoculated with Phoma lingam (Leptospsphaeria maculans). Phytoparasitica 42, 145-154. http://dx.doi.org/10.1007/s12600-013-0344-7

Liu A, Chen W, Li X. 2005. Changes in the postharvest physiology and lychee fruits latently infected by anthracnose fungus and the biological characteristics of the pathogenic fungus in the disease. Acta Horticult. 665, 365-371. http:// dx.doi.org/10.17660/ActaHortic.2005.665.45

Marsilio V, Campestre C, Lanza B, De Angelis M.2001. Sugar and polyol compositions of some European olive fruit varieties (Olea europaea L.) suitable for table olive purposes. Food Chem. 72, 485-490. http://dx.doi.org/10.1016/ S0308-8146(00)00268-5

Medina E, Brenes M, Romero C, García A, Castro A. 2007. Main Antimicrobial Compounds in Table Olives. J. Agric. Food Chem. 55, 9817-9823. https://doi.org/10.1021/ jf0719757

Menz G, Vriesekoop F. 2010. Physical and chemical changes during the maturation of Gordal Sevillana olives (Olea europaea L., cv. Gordal Sevillana). J. Agric. Food Chem. 58, 4934 4938. http://dx.doi.org/10.1021/jf904311r

Moral J, Xavier C, Roca LF, Romero J, Moreda W, Trapero A. 2014. Olive anthracnose and its effect on olive oil quality. Grasas Aceites 65, 1-16. http://dx.doi.org/10.3989/gya. 110913

Morales LO, Tegelberg R, Brosché M, Keinänen M, Lindfors A, Aphalo PJ. 2010. Effects of solar UV-A and UV-B radiation on gene expression and phenolic accumulation in Betula pendula leaves. Tree Physiol. 30, 923-934. http:// dx.doi.org/10.1093/treephys/tpq051

Morello JR, Motilva MJ, Ramos T, Romero MP. 2003. Effect of freeze injuries in olive fruit on virgin olive oil composition. Food Chem. 81, 547-553. http://dx.doi.org/10.1016/ S0308-8146(02)00488-0

Morello J R, Vuorela S, Romero M P, Motilva M J, Heinonen M. 2005. Antioxidant activity of olive pulp and olive oil phenolic compounds of the Arbequina cultivar. J. Agric. Food Chem. 53, 2002-2008. http://dx.doi.org/10.1021/jf048386a

Mousa Y, Gerasopoulos D. 1996. Effect of altitude on fruit and oil quality characteristics of "Mastoids" olives. J. Sci. Food Agric. 71, 345-350. https://doi.org/10.1002/(SICI)10970010(199607)71:3<345::AID-JSFA590>3.3.CO;2-K

Panagou E Z. 2006. Greek dry-salted olives: Monitoring the dry-salting process and subsequent physico-chemical and microbiological profile during storage under different 
packing conditions at 4 and $20^{\circ} \mathrm{C}$. LWT-Food Sci. Technol. 39, 323-330. http://dx.doi.org/10.1016/j.lwt.2005.02.017

Piscopo A, De Bruno A, Zappia A, Poiana M. 2014. Antioxidant activity of dried Green olives (Carolea cv.). LWT-Food Sci. Technol. 58, 49-54. http://dx.doi.org/10.1016/j.lwt.2014.03.013

Ramírez E, García-García P, de Castro A, Romero C, Brenes M. 2013. Debittering of black dry-salted olives. Eur. J. Lipid Sci. Technol. 115, 1319-1324. http://dx.doi.org/10.1002/ ejlt.201300167

Ramírez E, Medina E, Brenes M, Romero C. 2014. Endogenous enzymes involved in the transformation of oleuropein in Spanish table olive varieties. J. Agric. Food Chem. 62, 9569-9575. http://dx.doi.org/10.1021/jf5027982

Ramírez E, Gandul-Rojas B, Romero C, Brenes M, GallardoGuerrero L. 2015. Composition of pigments and colour changes in green table olives related to processing type. Food Chem. 166, 115-124. http://dx.doi.org/10.1016/j. foodchem.2014.05.154

Rigane G, Salem R, Sayadi S, Bouaziz M. 2011. Phenolic composition, isolation, and structure of a new deoxyloganic acid derivative from Dhokar and Gemri-Dhokar olive cultivars. J. Food Sci. 76, C965-C973. http://dx.doi. org/10.1111/j.1750-3841.2011.02290.x

Romero C, Bakker J. 2000. Anthocyanin and colour evolution during maturation of four port wines: effect of pyruvic acid addition. J. Sci. Food Agric. 81, 252-260. https:// doi.org/10.1002/1097-0010(20010115)81:2<252::AIDJSFA810 $>3.0$. CO $; 2-5$

Romero C, García P, Brenes M, García A, Garrido A. 2002. Phenolic compounds in natural black Spanish olive varieties. Eur. Food Res. Technol. 215, 489-496. http://dx.doi. org/10.1007/s00217-002-0619-6
Romero C, Brenes M, García P, García A, Garrido A. 2004. Polyphenol changes during fermentation of naturally black olives. J. Agric. Food Chem. 52, 1973-1979. http:// dx.doi.org/10.1021/jf030726p

Romero C, Ruiz-Méndez M V, Brenes M. 2016. Bioactive compounds in virgin olive oils of the PDO Montoro-Adamuz. J. Am. Oil Chem. Soc. 93, 665-672. https://doi.org/10.1007/ s11746-016-2803-z

Sozbilen G S, Baysal A H. 2016. Microbial profile and bacterial characterization of naturally debittered Hurma olives compared to non-debittered Erkence variety during ripening period. Int. J. Food Sci. Technol. 51, 2099-2105. http:// dx.doi.org/10.1111/ijfs. 13187

Spayd S E, Tarara J M, Mee D L, Ferguson J C. 2002. Separation of sunlight and temperature effects on the composition of Vitis vinifera cv. Merlot berries. Am. J. Enol. Viticult. 53, 171-182.

Susamci E. 2011. Effect of different storage and temperature conditions postharvest durability of Karaburun Hurma Table Olives. Olive Research Institute. Publication no 215. (TAGEM/GY/10/03/01/170). Izmir, Turkey.

Talhaoui N, Gómez-Caravaca A M, León L, De la Rosa R, Fernández-Gutiérrez A, Segura-Carretero A. 2015. Pattern of variation of fruit traits and phenol content in olive fruits from six different cultivars. J. Agric. Food Chem. 63, 10466-10476. http://dx.doi.org/10.1021/acs.jafc. $5 \mathrm{~b} 04315$

Zoratti L, Jaakola L, Haggman H, Giongo L. 2015. Anthocyanin profile in berries of wild and cultivated Vaccinium spp. along altitudinal gradients in the Alps. J. Agric. Food Chem. 63, 8641-8650. http://dx.doi.org/10.1021/acs.jafc. $5 \mathrm{~b} 02833$ 